\title{
Study on the Applications of 3D Visualization System of Geographic Information
}

\author{
Yan $\mathrm{Li}^{1, \mathrm{a}}$ \\ ${ }^{1}$ Zhengzhou Vocational College of Industrial Safety, Zhengzhou University, Zhengzhou450000, \\ China \\ ayanzi@163.com
}

Keywords: geographic information; 3D visualization system; application; research

Abstract. In information system, 2D geographic information has insurmountable shortcomings. It is difficult to meet people' s demand for 3D real information. With constant development of scientific and technological information, 3D visualization system emerged. 3D visualization system is to solve problems that are difficult to overcome for 2D system, on the basis of 2D system. Due to these characteristics of $3 \mathrm{D}$ visualization system, it plays a prominent role in geographic information processing. For this end, in this paper, the practical application of 3D visualization system of geographic information is studied.

\section{Introduction}

Practical studies on 3D visualization system of geographic information are in fact characteristic problems in the study of geographic information system. 3D visualization system of geographic information has diversified characteristics. It can input, store, edit, query data information and analyze the data model, etc. within 3D space. The emergence of 3D visualization system of geographic information provides possibility for people to explore ground surface environment and plays an important role in such aspects as urban construction, military affairs and environment, etc.

\section{The Theoretical Basis of 3D Visualization of Geographic Information System}

Geographic Information System

Geographic information system is also known as GIS system. This system manages spatial geographic data comprehensively, with the aid of computer technology. Under scientific spatial data planning, combined with multiple subjects such as informatics, space science and geography, spatial geographical data are input, output, queried and analyzed, etc. Modern GIS allows querying spatial data and solving five problems: location, the coordinate of information; condition, where an entity satisfying the condition is; trend, the possibility of occurrence of things; mode, revealing the relationship between entities in space; simulation, simulating possible location changes according to the variation trend of the spatial data of things [1]. The block diagram of GIS is as follows:

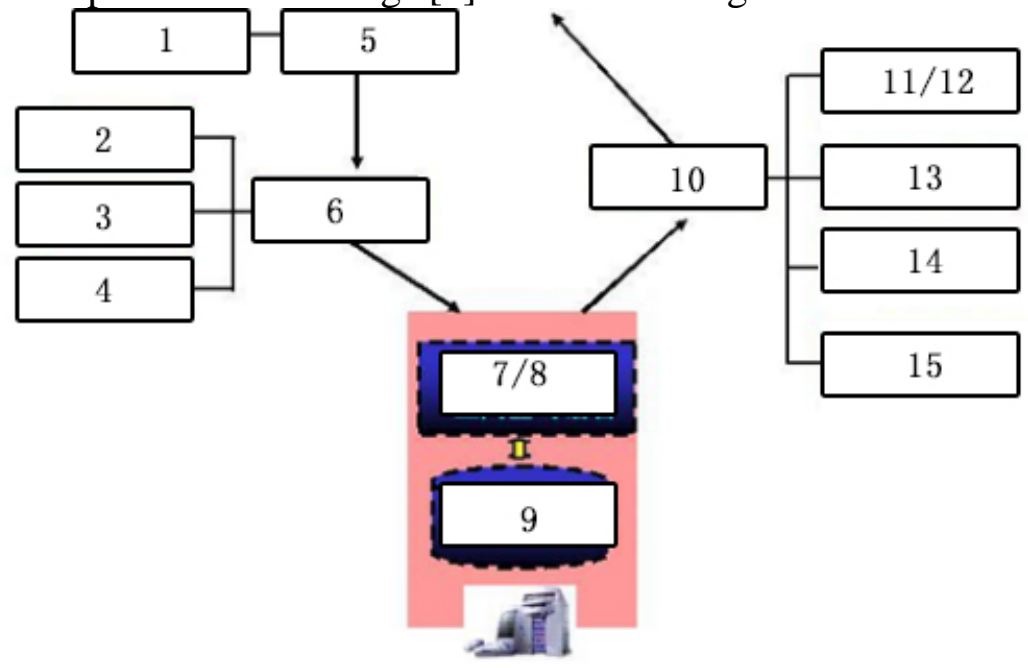


1. Graph-attribute; 2. Limitation of attribute; 3. Limitation of spatial topology; 4. Combination of the two; 5. Query mode; 6. Query condition; 7. GIS software; 8. Spatial query language; 9. Spatial database; 10 Query results; 11 . Statistical results; 12 Graph, table and text; 13. New layer; 14.New attribute field is added to the attribute database; 15. Conspicuous display with flash and color, etc.

Fig. 1 The Block Diagram of GIS

$3 \mathrm{D}$ visualization technology

Along with the gradual development of information technology, 3D visualization technology has been researched and developed on the basis of 2D technology. Relying on technical advantages, 3D visualization technology is widely used in different fields and directly affects the development of GIS in China. At present, 3D visualization technology can be effectively applied to military affairs, aviation, aerospace, geological exploration, art and other fields. It is technically implemented through graphic transformation and real induction figures, etc. Graphic transformation is to generate complex graphs using graphic transformation means, on the basis of computer graphics. Visualized graphic transformation can be realized through geometric transformation. Generally speaking, geometric transformation includes translation and rotation. In essence, these graphic transformations are matrix transformation. 3D visualized realistic graphs refer to realistic graphs with 3D shapes generated by a computer. This technology can be widely applied in data field visualization, movies and animation production and games, etc. [2] Below is a 3D visualization graph of a computer room:

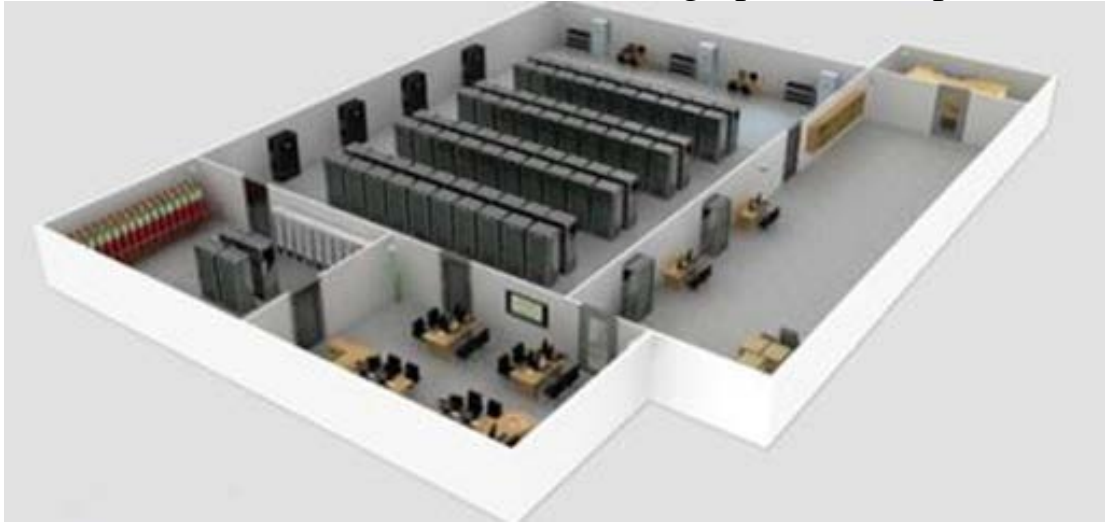

Fig. 2 A 3D Visualization Graph of a Computer Room

\section{The Practical Application of the 3D Visualization System of Geographic Information}

To apply 3D visualization system of geographic information to actual engineering, geographic information functions in different fields can be developed, according to the characteristics of this information technology system. In this article, the practical application of 3D visualization system of geographic information of School of Engineering, Zhengzhou University is studied. The proposed visualization system is composed of two parts, campus 2D GIS and 3D GIS.

2.1 An analysis of system characteristics

To study the 3D visualization system of geographic information in the college, in system design, first of all, it is necessary to clarify the characteristics of the system. The proposed system has four characteristics: first of all, the system has strong actual extensibility. In actual design, it can be directly extended from 2D to 3D geographic information system and reflect the object encapsulation of object-oriented technology, as well as the diversity of system design. Secondly, the system is easy to operate. The proposed 3D visualization system design can meet the demands of teachers and students, with Windows programs menu as the benchmark, to help students learn and use. Thirdly, the modularization of program design. The design of system is able to regard it as a module at any time and apply it to the program use. Fourthly, it realizes 3D [3].

2.2 The structure and display of 3D graphs

The structure of the 3D visualization system of geographic information of Zhengzhou University is analyzed, as shown in the table below: 
Table 1 The 3D Visualization System of Geographic Information

\begin{tabular}{|c|c|c|c|c|c|c|c|}
\hline \multicolumn{8}{|c|}{$\begin{array}{l}\text { The 3D Visualization System of Geographic Information of } \\
\text { Zhengzhou University }\end{array}$} \\
\hline \multicolumn{4}{|c|}{ 2D GIS of Zhengzhou University } & \multicolumn{4}{|c|}{ 3D GIS of Zhengzhou University } \\
\hline $\begin{array}{l}\quad \text { La } \\
\text { yer } \\
\text { displa } \\
\text { y }\end{array}$ & $\begin{array}{l}\quad \text { Geogra } \\
\text { phic } \\
\text { informatio } \\
\text { n query } \\
\text { module }\end{array}$ & $\begin{array}{l}\text { Map } \\
\text { output } \\
\text { module }\end{array}$ & $\begin{array}{l}\quad 3 \mathrm{D} \\
\text { query } \\
\text { modul } \\
\text { e }\end{array}$ & $\begin{array}{l}\quad \text { Real } \\
\text {-time } \\
\text { roaming } \\
\text { module }\end{array}$ & $\begin{array}{l}\quad \text { Rotati } \\
\text { on } \\
\text { operation } \\
\text { module }\end{array}$ & $\begin{array}{l}\text { Anima } \\
\text { tion } \\
\text { module }\end{array}$ & $\begin{array}{l}\text { Modificati } \\
\text { on module }\end{array}$ \\
\hline
\end{tabular}

The overall visualization system mainly can be divided into 2D and 3D GISs. The content contained in different systems varies. For example, a 2D system may contain layer reality, geographic information query, map output module and 3D query module. While a 3D system may contain real-time roaming module, rotation operation module, animation module and modification module, etc. Research on actual systems can conceive according to the system design and acquire data. In the early stage of system function implementation, data are acquired and vectorization is carried out according to maps. The most critical step is to build a spatial database. Meanwhile, to implement various functions, a modularized design is adopted. A single module can operate independently and provide a technical guarantee for system operation [4].

\section{$2.33 \mathrm{D}$ function design}

\subsubsection{D animation module}

The actual design of 3D GIS is mainly to realize 3D modeling, with the aid of OpenGL function in VB language. When invoking this function, it is necessary to clarify the database type and file type contained in this function. The OpenGL database is invoked in VB engineering, including DLL dynamic link libraries, OCG controls and EXE files. For these files, a 3D animation module design is conducted. In the design of scale module, it is required to design realistically according to users' demands. The user perspective is a key to system research. Such a user-centered design form is actually a kind of user attempt. Users can use the mouse and keyboard, choose a suitable space perspective and enjoy roaming in 3D space. Apart from the user perspective, a system design with designated routes as the criterion can also be used, for example, the animation form from a bird's eye, which makes the internal layout of campus clear in a glance. [5]

2.3.2 Modification module

In 3D GIS, research on modification module is arguably an important part and known as 3D realistic graphics. Under such a drawing form, the authenticity of GIS can be enhanced. The modification module mainly contains graph blanking, texture mapping and lighting material, etc. To analyze graph blanking, in the analysis of spatial graphic location, some objects may be covered by other objects. In the drawing of 3D graphs, it is necessary to restore the covered objects in 3D space. So in order to draw real scenes, it is necessary to clarify such a realistic covering relationship. The value and meaning of such a blanking comparison function is shown as follows:

Table 2: The Value and Meaning of Comparison Function

\begin{tabular}{cc}
$\begin{array}{c}\text { Parameter } \\
\text { Name }\end{array}$ & Meaning \\
\hline GL_NEVE & The old depth value remains unchanged. \\
GL_LESS & $\begin{array}{l}\text { If the new value is smaller than the old one, the new } \\
\text { value will completely replace the old one. } \\
\text { When the new value is equal to the old one, the new } \\
\text { value will replace the old one. } \\
\text { When the new value is smaller than or equal to the } \\
\text { GL_EQUA } \\
\text { GL_LEQU }\end{array}$ \\
old one, the new value will replace the old one.
\end{tabular}


Besides, in the 3D visualization applications of geographic information of Zhengzhou University, special attention must be paid to texture mapping in the environment. Spatial surface features in the campus GIS are mainly building facilities. These different types of facilities are difficult to sketch in detail. Their visualization degree in 3D information system is low. As for this problem, to reflect all objects in the system as far as possible, it is needed to adopt texture mapping technology to process realistic graphs in different regions and different scenes [6].

In addition, in lighting and material, etc., the 3D visualization system can be perfected. The system design in this part is very necessary, because objects in 3D space have different degrees of light and shade. Spatial geometric graphs are inconsistent, either. To enhance the 3D visualization authenticity in GIS, we need to show the true state of spatial surface features through their shape, color and material.

\section{Conclusion}

To sum up, 3D visualization technology of geographic information manages spatial geographic data comprehensively, with the aid of computer technology. Under scientific spatial data planning, combined with multiple subjects such as informatics, space science and geography, spatial geographical data are input, output, queried and analyzed, etc. To apply 3D visualization system of geographic information to actual engineering, geographic information functions in different fields can be developed, according to the characteristics of this information technology system. In this article, the practical application of 3D visualization system of geographic information of School of Engineering, Zhengzhou University is studied. The structure and display of 3D graphs are analyzed and a 3D function design is carried out.

\section{References}

[1]Yiu L T, Wang Y, Danheiser R L. Study on the interconnection and interoperability between urban 3D visualization and geographic information system[J]. Journal of Applied Sciences, 2003, 6(1):3535-3537 vol.6.

[2]Castrillón M, Jorge P A, López I J, et al. Forecasting and visualization of wildfires in a 3D geographical information system[J]. Computers \& Geosciences, 2011, 37(3):390-396.

[3]Liu C T, Lin-Lin L I. Application of 3D Geographic Information System in Military[J]. Beijing Surveying \& Mapping, 2014.

[4]Koller D, Lindstrom P, Ribarsky W, et al. Virtual GIS: a real-time 3D geographic information system[J]. 1995.

[5]Mat R C, Shariff A R M, Pradhan B, et al. A Comparison between four-tier framework and three-tier framework for online applications of 3D GIS visualization[J]. Life Science Journal, 2013.

[6]Blair J L, Mccrory P A, Oppenheimer A D H, et al. We present a Geographic Information System (GIS) of a new 3-dimensional (3D) model of the subducted Juan de Fuca Plate beneath western North America and associated seismicity of the Cascadia subduction system. We also provide a 3D fly-through animation of[J]. Center for Integrated Data Analytics Wisconsin Science Center, 2011. 